\title{
Aquathermolysis of heavy crude oil with ferric oleate catalyst
}

\author{
Yun-Rui $\mathrm{Li}^{1} \cdot$ Qiu-Ye $\mathrm{Li}^{1} \cdot$ Xiao-Dong Wang ${ }^{1} \cdot{\text { Lai-Gui } \mathrm{Yu}^{1} \cdot \text { Jian-Jun Yang }}^{1}$
}

Received: 28 November 2017 / Published online: 17 July 2018

(C) The Author(s) 2018

\begin{abstract}
Oil-soluble catalysts could be of special significance for reducing the viscosity of heavy crude oil, because of their good dispersion in crude oil and high catalytic efficiency toward aquathermolysis. Ferric oleate was synthesized and applied as catalyst in the aquathermolysis reaction of Shengli heavy oil. It was found that ferric oleate was more efficient for heavy oil cracking than Co and Ni oleates. Besides, it was superior to oleic acid and inorganic ferric nitrate and achieved the highest viscosity reduction rate of up to $86.1 \%$. In addition, the changes in the components of Shengli heavy oil before and after aquathermolysis were investigated by elemental analysis, Fourier transform infrared spectrometry, and ${ }^{1} \mathrm{H}$ nuclear magnetic resonance spectroscopy. Results indicated that ferric oleate contributed to a significant increase in the content of light components and decrease in the content of resin, $\mathrm{N}$ and $\mathrm{S}$. The as-prepared ferric oleate showed good activity for reducing the viscosity and improving the quality of the heavy crude oil, showing promising application potential in aquathermolysis of heavy crude oil.
\end{abstract}

Keywords Heavy oil · Viscosity reduction $\cdot$ Aquathermolysis $\cdot$ Ferric oleate $\cdot$ Catalyst

\section{Introduction}

With the excessive exploitation and rapid consumption of the conventional oil and gas resources, the exploitation of heavy crude oil and other low-grade oil and gas resources is attracting more and more attention (Huc 2010). The key issue of heavy crude oil extraction is to reduce the viscosity and increase its fluidity, and catalytic aquathermolysis could have potential for viscosity reduction in heavy crude oil (Maity et al. 2010). Early in the 1980s, Hyne and coworkers found that transition metals $\mathrm{Ni}$ and $\mathrm{Co}$ had a positive effect on the aquathermolysis of heavy oil (Chivers et al. 1980; Hyne et al. 1982). Clark et al. (1987, 1983) used thiophene and tetrahydrothiophene as the model compounds and studied the influence of transition metals on the hydrothermal cracking of heavy crude oil, and they found that group VIII transition metals contributed to

Edited by Xiu-Qin Zhu

Qiu-Ye Li

qiuyeli@henu.edu.cn

Jian-Jun Yang

yangjianjun@henu.edu.cn

1 Engineering Research Center for Nanomaterials, Henan University, Kaifeng 475004, China significantly enhancing the desulfurization of heavy crude oil. Chen et al. $(2010 ; 2013)$ proposed seven possible mechanisms to explain the viscosity reduction in heavy oil by aquathermolysis. These include hydrogenation, pyrolysis, depolymerization, isomerization, ring-opening, esterification, reconstruction and oxygenation. Needless to say, the selection of proper aquathermolysis catalysts is essential for achieving efficient hydrothermal cracking of heavy crude oil. The frequently used aquathermolysis catalysts mainly include water-soluble catalysts, oil-soluble catalysts, dispersed catalysts and solid acid catalysts (Maity et al. 2010). Among them, the oil-soluble catalysts often exhibit a high efficiency, because they can be uniformly dispersed in oil to promote the catalytic aquathermolysis reaction.

In recent years, iron-based oil-soluble catalysts have been extensively studied due to their being environmentfriendly, lower cost and high efficiency. It has been found that iron naphthenate (Fan et al. 2006) is able to decrease the content of heavy components, thereby effectively reducing the viscosity of the heavy crude oil produced at Shengli Oilfield (Dongying, China). Besides, iron(III) tris(acetylacetonate) complex (Galukhin et al. 2015) catalyst can promote the transformation of high-molecularweight components of heavy crude oil at an elevated temperature of $250{ }^{\circ} \mathrm{C}$ and an initial pressure of $3 \mathrm{MPa}$, 
thereby significantly reducing the viscosity. Moreover, some researchers found that long-chain aromatic sulfonic iron (Wang et al. 2010; Li et al. 2013) can promote the aquathermolysis of heavy crude oil. These iron-based oilsoluble catalysts play the catalytic role of the transition metal and emulsification of organic ligands. But the reported system needs to introduce another surfactant in order to improve the contact between the catalyst and heavy oil.

Through a literature search, we found that the oleic acid ligand possessed good contact with heavy oil (Jeon et al. 2011). It has been reported that nickel oleate, cobalt oleate and molybdenum oleate (Chen et al. 2010; Wen et al. 2007) had been used to reduce the viscosity of Liaohe heavy oil and could achieve a good catalytic effect. In addition, ferric oleate (Peng 2014) exhibited efficiency for the viscosity reduction in Liaohe heavy crude oil by catalytic upgrading at $350-400{ }^{\circ} \mathrm{C}$. However, the high temperature is unfavorable for maintaining stable catalytic efficiency and it effectively reduces production, as well as increasing the cost. Therefore, it is more meaningful to study the catalytic performance at a lower temperature.

In this study, the ferric oleate was prepared and used for the aquathermolysis of the Shengli heavy crude oil at a lower temperature. The ferric oleate exhibited higher activity than either nickel oleate or cobalt oleate. And the viscosity reduction rate of the heavy crude oil sample was up to $86.1 \%$ at a mass fraction of $10 \mathrm{wt} \%$. The heavy crude oil samples before and after aquathermolysis were studied in detail by saturate, aromatic, resin and asphaltene (SARA), EL, ${ }^{1} \mathrm{H}-\mathrm{NMR}$, FT-IR examination and water contact angles. We also investigated the reaction mechanism of the ferric oleate.

\section{Experimental section}

\subsection{Synthesis and characterization of ferric oleate}

Excessive iron(III) nitrate nonahydrate was dissolved in distilled water to form a saturated solution in a flask. $\mathrm{NaOH}$ aqueous solution $(1 \mathrm{~mol} / \mathrm{L})$ was slowly added into the resultant saturated solution under continuous stirring until the $\mathrm{pH}$ value of the mixture solution reached $4-6$, followed by the addition of oleic acid at an oleic acid/ferric nitrate molar ratio of 1.8:1. The reactants were heated to $120{ }^{\circ} \mathrm{C}$ and stirred for $3 \mathrm{~h}$ to allow the completion of reaction. At the end of the reaction, the upper organic layer was separated using a funnel and washed three times with $n$-heptane, and then vacuum dried at $70{ }^{\circ} \mathrm{C}$ for $24 \mathrm{~h}$. After the solvent was evaporated, the final product ferric oleate, a reddish-brown viscous oil, was obtained. Nickel oleate and cobalt oleate for comparative studies were synthesized in the same manner with nickel nitrate and cobalt chloride hexahydrate as the metal sources.

The as-synthesized ferric oleate catalyst was dissolved in $\mathrm{CHCl}_{3}$ solution and spread evenly on a $\mathrm{KBr}$ pellet to form a thin film. The resultant thin film of ferric oleate was characterized by Fourier transform infrared spectrometry (FT-IR; VERTEX 70, Bruker Optics). The thermal stability of the as-synthesized ferric oleate catalyst was determined by thermogravimetric analysis (TGA, METTLER TOLEDO, TGA/SDTA851e) in air (heating rate: $10{ }^{\circ} \mathrm{C} /$ min; up to $1000{ }^{\circ} \mathrm{C}$ ). The metal content of the as-synthesized ferric oleate was measured by inductively coupled plasma-atomic emission spectrometry (ICP-AES, PerkinElmer, Optima 2100DV). The carbon and hydrogen content was determined by Elemental Analyzer (EA, vario EL cube).

\subsection{Catalytic aquathermolysis reaction of heavy crude oil}

The heavy oil used for this research was the 3\# heavy crude oil from Shengli Oilfield, China. Its properties and composition are given in Table 1 . The aquathermolysis of the heavy crude oil was conducted at $200{ }^{\circ} \mathrm{C}$ for $24 \mathrm{~h}$. Briefly, $50 \mathrm{~g}$ of the heavy crude oil was mixed with different dosages of the as-synthesized ferric oleate catalyst in an autoclave; the resultant mixture was then heated to $200{ }^{\circ} \mathrm{C}$ and held for $24 \mathrm{~h}$. (The catalyst does not contain water, and the heavy crude oil contains only $12.0 \mathrm{wt} \%$ water). Upon completion of the aquathermolysis reaction, the viscosity of the oil samples was measured at $50{ }^{\circ} \mathrm{C}$ with a viscometer (Brookfield-DV-III). Five repeat aquathermolysis reactions were conducted for each oil sample, and the averaged

Table 1 The properties and composition of the heavy oil sample

\begin{tabular}{ll}
\hline Properties & 3\# Oil sample \\
\hline Viscosity, $\mathrm{mPa} \mathrm{s}$ & 173,400 \\
Density at $20^{\circ} \mathrm{C}, \mathrm{g} / \mathrm{cm}^{3}$ & 0.9834 \\
Water content, wt $\%$ & 12.0 \\
Group composition, wt $\%$ & \\
$\quad$ Saturates & 31.1 \\
Aromatics & 32.7 \\
Resin & 32.7 \\
$\quad$ Asphaltene & 3.5 \\
Element content, wt $\%$ & \\
$\mathrm{~N}$ & 0.82 \\
$\mathrm{C}$ & 84.04 \\
$\mathrm{H}$ & 12.54 \\
$\mathrm{~S}$ & 2.59 \\
$\mathrm{~N}_{\mathrm{H}} / \mathrm{N}_{\mathrm{C}}$ & 1.79 \\
\hline
\end{tabular}


viscosity data are reported in this article. The viscosity reduction ratio is calculated as $\Delta \eta=\left(\eta_{0}-\eta\right) / \eta_{0} \times 100 \%$ $\left(\Delta \eta, \eta_{0}\right.$ and $\eta$ are the viscosity reduction rate, the viscosity of the heavy crude oil before and after aquathermolysis reaction).

\subsection{Characterization of oil samples}

\subsubsection{Separation of the four-group composition in oil samples}

The heavy crude oil was vacuum dried at $40-50{ }^{\circ} \mathrm{C}$ for $24 \mathrm{~h}$. The four-group SARA compositions of the oil samples were separated with $\gamma-\mathrm{Al}_{2} \mathrm{O}_{3}$ column chromatography, by the China petroleum standard method (NB/SH/T 0509-2010). The flow diagram for the separation is illustrated in Fig. 1.

\subsubsection{Elemental analysis}

The elemental composition (C, H, N and S) of the heavy crude oils before and after aquathermolysis and their fourgroup composition (saturated, aromatic, resin and asphaltene; denoted as SARA) were determined by elemental analysis (EA, Elemental Analyzer vario EL cube).

\subsubsection{Fourier transform infrared spectroscopy}

The oil samples and their heavy components (resin and asphaltene) before and after aquathermolysis were dissolved in $\mathrm{CCl}_{4}$ and spread evenly on $\mathrm{KBr}$ pellets to form a thin film after solvent evaporation for FT-IR spectroscopy.

\subsection{4 ${ }^{1} \mathrm{H}$ NMR}

The ${ }^{1} \mathrm{H}$ NMR spectra of oil samples and heavy component (resin and asphaltene) before and after reaction were recorded on an Avance III $\mathrm{HD} 400 \mathrm{MHZ}$, and $\mathrm{CDCl}_{3}$ was used as the solvent (with TMS as the internal reference material).

\subsubsection{Water contact angle}

A contact angle meter (Kruss, DSA100S) was employed to determine the water contact angles of the heavy crude oil with ferric oleate.

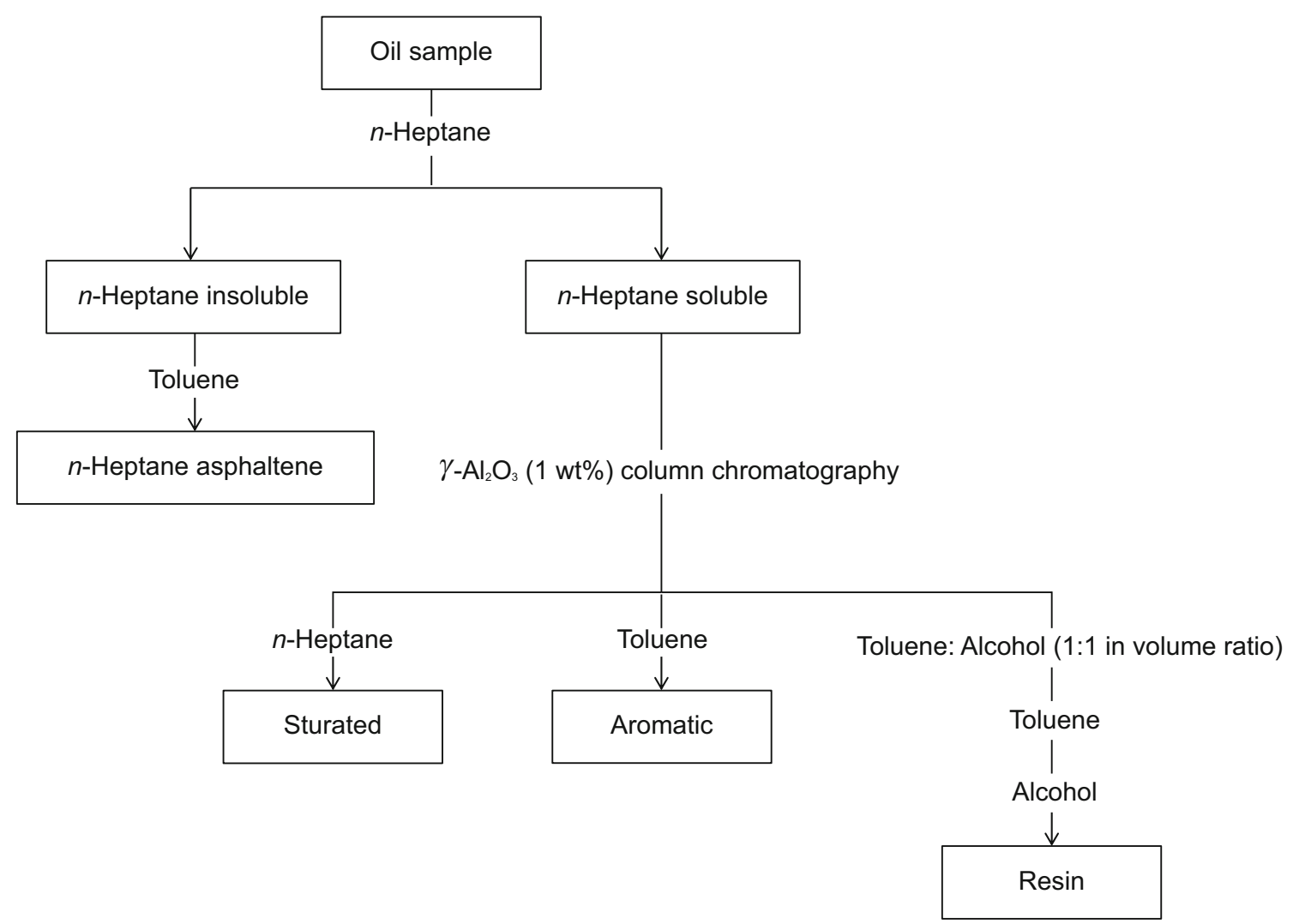

Fig. 1 The flow diagram for the separation of four-group composition in oil sample 


\section{Results and discussion}

\subsection{Characterization of ferric oleate}

The FT-IR spectra of oleic acid and ferric oleate are shown in Fig. 2. Ferric oleate exhibits characteristic absorbance peaks of $v\left(\mathrm{COO}^{-}\right)$at $1711,1592,1458$, and $1419 \mathrm{~cm}^{-1}$. The characteristic peaks of metal carboxylates are in the range of $1610-1540 \mathrm{~cm}^{-1}$ for the antisymmetric stretching vibration and $1464-1360 \mathrm{~cm}^{-1}$ for the symmetric stretching vibration. (The latter was often split into two or three broad peaks.) The peak at $1711 \mathrm{~cm}^{-1}$ is assigned either to the symmetric stretching vibration of free oleic acid or to the asymmetrical stretching vibration of unidentate carboxylate. The absorption peak at $733-723 \mathrm{~cm}^{-1}$ is assigned to the $-\left(\mathrm{CH}_{2}\right)_{n^{-}}(n \geq 4)$ of the long-alkyl side chain of the catalyst (Bronstein et al. 2007; Palchoudhury et al. 2011). Moreover, the coordination modes of the metal carboxylate can be deduced by the frequency difference between the antisymmetric and symmetric stretching vibration of $v\left(\mathrm{COO}^{-}\right), \Delta$, in the range of $1300-1700 \mathrm{~cm}^{-1}$. In this research, it could be deduced that the iron carboxylate is iron-coordinated or bridging-coordinated, because $\Delta=134 \mathrm{~cm}^{-1}\left(110<\Delta<200 \mathrm{~cm}^{-1}\right)$ (Palchoudhury et al. 2011). Therefore, the ferric oleate catalyst was prepared successfully.

The TGA/DTG curves of the as-synthesized ferric oleate and oleic acid are shown in Fig. 3a. The mass loss in the range of $150-292{ }^{\circ} \mathrm{C}$ (Fig. 3a, region a) is due to the dissociation of two oleate ligands from ferric oleate, and the mass loss at $292-354{ }^{\circ} \mathrm{C}$ (Fig. 3a, region b) is due to the dissociation of the remaining one oleate ligand, and the DTG curve peak areas ratio of the two mass loss region is close to 2:1 (Palchoudhury et al. 2011). The mass loss at $\sim 354{ }^{\circ} \mathrm{C}$ is due to desorption of decomposed oleic acid

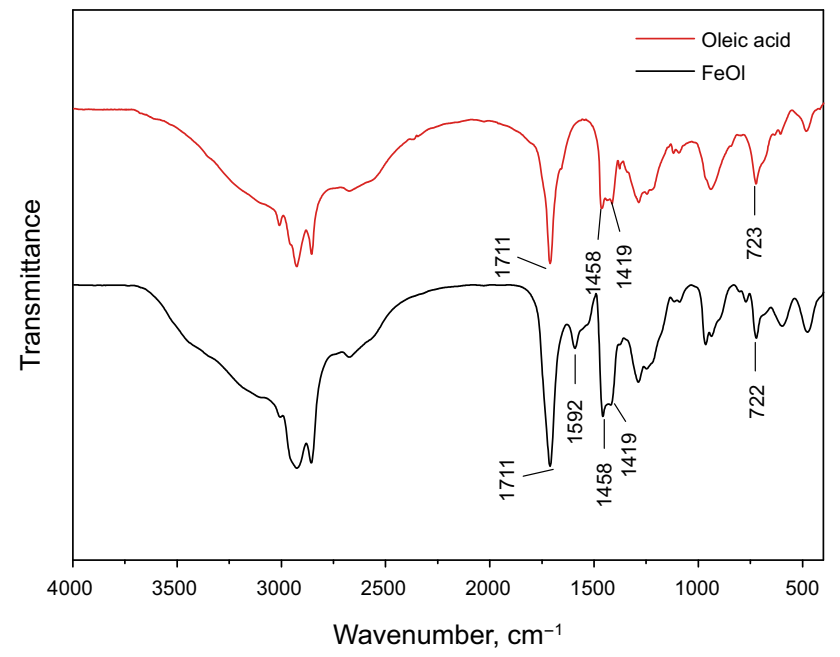

Fig. 2 FT-IR spectra of oleic acid and ferric oleate $(\mathrm{FeOl})$ ligands and evaporation of remaining organic components (Fig. 3a, region c). The weight loss in the range of 356-389 ${ }^{\circ} \mathrm{C}$ (Fig. 3a, region c) might be due to the decomposition of impurity ferric nitrate (Shanmugam et al. 2003). The trace weight loss around $100{ }^{\circ} \mathrm{C}$ is derived from the evaporation of solvent. The results of thermogravimetry analysis are indicated that there are three oleic acid ligands on an iron ion.

The elemental analysis $(\mathrm{C}, \mathrm{H})$ and ICP data $(\mathrm{Fe})$ of the as-synthesized catalyst are shown in Table 2 . The results show that the $\mathrm{C} / \mathrm{H}$ ratio of catalyst we synthesized is close to the theoretical structure of $\mathrm{Fe}(\text { oleate })_{3}$. And the residual value calculated by theory is $10.4 \mathrm{wt} \%$, which is close to $14.8 \mathrm{wt} \%$ that obtained from the TGA/DTG curve (Fig. 3a). Based on the results of FT-IR and TGA/DTG analysis, we can infer that ferric oleate exhibits an ironcoordination mode. The molecular structure of ferric oleate is shown in Fig. 4.

In combination with the TGA/DTG curve of oleic acid in Fig. 3b, we can, therefore, draw the conclusion that ferric oleate has good thermal stability and has promising applications as an aquathermolysis catalyst. The long-chain structure of the oleate catalyst is helpful to enhance the contact with heavy crude oil, thereby improving the aquathermolysis catalytic efficiency.

Nickel oleate and cobalt oleate prepared in the same manner also exhibit good thermal stability (Their FT-IR spectra and TGA/DTG curves are presented in Figs. 5 and 6). Namely, the oleic ligand of nickel oleate and cobalt oleate is stable at $200{ }^{\circ} \mathrm{C}$, which means that they could be potential moderate-temperature aquathermolysis catalysts for heavy crude oil.

\subsection{Catalytic aquathermolysis of heavy crude oil}

\subsubsection{Effect of different oleates on the aquathermolysis of heavy crude oil}

Three different oleate catalysts (ferric oleate, nickel oleate and cobalt oleate) were used to catalyze the aquathermolysis reaction of the heavy crude oil, and the dosage of the catalyst was fixed at $1.0 \mathrm{wt} \%$ (mass fraction; the same hereafter). As shown in Fig. 7, the viscosity reduction ratio without catalyst was $19.0 \%$, due to the thermal cracking of the heavy crude oil. When ferric oleate, nickel oleate and cobalt oleate were separately introduced into the heavy crude oil, the viscosity reduction ratio was 34.0, 24.3, and $3.3 \%$, respectively. Ferric oleate had the best performance in reducing the viscosity of the heavy crude oil, because it contains three oleic acid ligands and exhibited good dispersion and contact with the heavy crude oil. In addition, cobalt can be associated with the heavy components of the heavy crude oil at high temperature, and this accounts for 


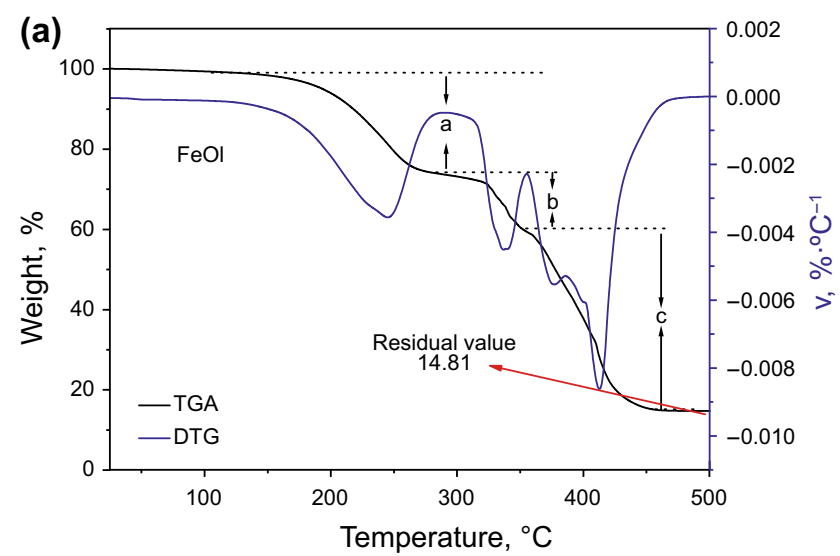

Fig. 3 TGA/DTG curves of ferric oleate (a) and oleic acid (b)

Table 2 Elemental (C, H, Fe) analysis data of the synthesized catalysts

\begin{tabular}{|c|c|c|c|c|c|}
\hline Sample & $\mathrm{C}, \mathrm{wt} \%$ & $\mathrm{H}, \mathrm{wt} \%$ & $\mathrm{Fe}, \mathrm{wt} \%$ & $\mathrm{~N}_{\mathrm{C}} / \mathrm{N}_{\mathrm{H}}$ & $\mathrm{N}, \mathrm{wt} \%$ \\
\hline $\begin{array}{l}\text { Ferric } \\
\text { oleate }(\mathrm{FeOl})\end{array}$ & 61.64 & 9.12 & 10.01 & 0.56 & 0.43 \\
\hline${ }^{\mathrm{a}} \mathrm{Fe}(\text { oleate })_{3}$ & ${ }^{a} 72.08$ & ${ }^{\mathrm{a}} 11.01$ & a 6.23 & 0.55 & 0 \\
\hline
\end{tabular}

${ }^{\mathrm{a}}$ The theoretical C, H, Fe content of ferric oleate
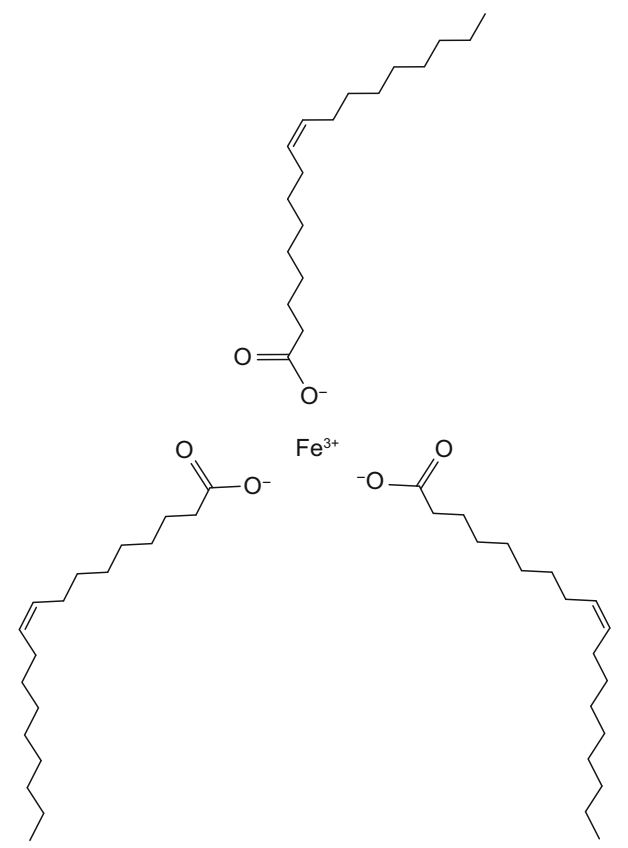

Fig. 4 Molecular structure of ferric oleate $(\mathrm{FeOl})$

its poorest viscosity-reduction ability among the three oleate catalysts (Hong et al. 2001).

In order to study the effect of $\mathrm{Fe}^{3+}$ and the long-alkyl chain of the ferric oleate catalyst on the aquathermolysis of
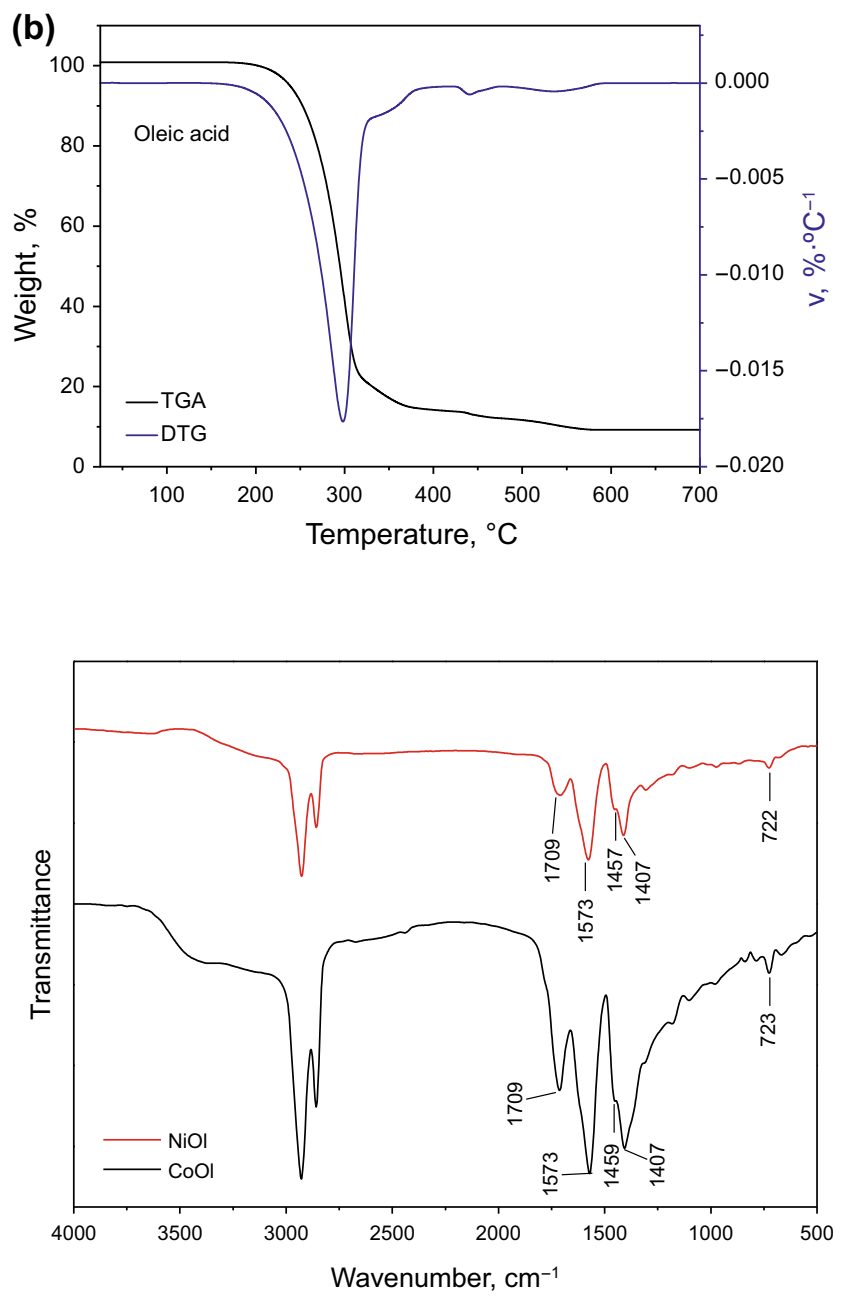

Fig. 5 FT-IR spectra of nickel oleate $(\mathrm{NiOl})$ and cobalt oleate $(\mathrm{CoOl})$

the heavy crude oil, we selected water-soluble iron nitrate nonahydrate and oleic acid as the reference and conducted comparative experiments at a catalyst dosage of $0.50 \mathrm{wt} \%$ (ferric oleate), $0.45 \mathrm{wt} \%$ (oleic acid) and $0.35 \mathrm{wt} \%$ (nonahydrate iron nitrate), respectively. (The catalyst dosage is calculated based on the content of Fe listed in Table 2.) As shown in Fig. 8, ferric oleate exhibits a much higher viscosity reduction ratio than oleic acid. The viscosity of the heavy crude oil is reduced after aquathermolysis in the presence of oleic acid, which could be due to the dilution and emulsification function of oleic acid. (Oleic acid can reduce the water surface tension to $42.49 \mathrm{mN} / \mathrm{m}$.) Ferric oleate contributes significantly to the viscosity reduction in the heavy crude oil. This is because, on the one hand, $\mathrm{Fe}^{3+}$ can catalyze the aquathermolysis of the heavy crude oil well; on the other hand, the long-alkyl chain exhibits an emulsification function (ferric oleate can reduce the water surface tension to $33.82 \mathrm{mN} / \mathrm{m}$ ), thereby showing greatly increased viscosity-reduction ability. In contrast to oleic acid and ferric oleate, iron nitrate nonahydrate leads to an 


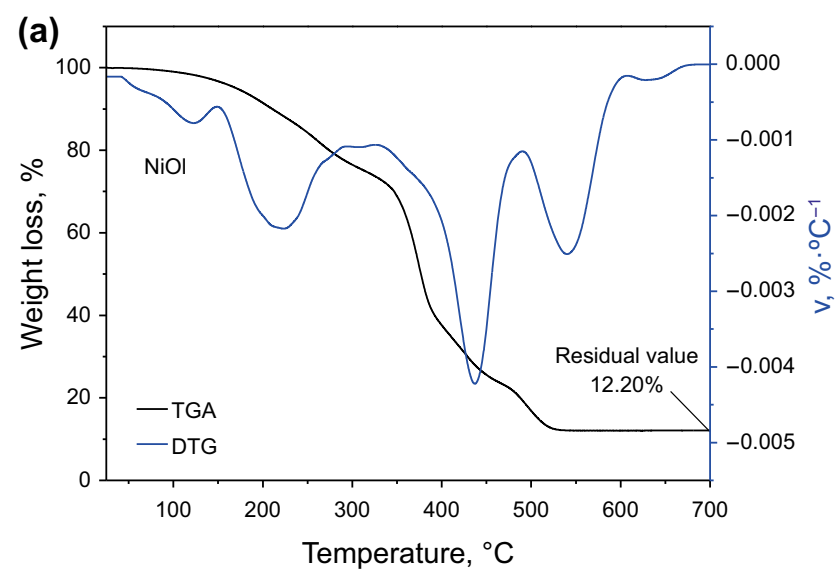

Fig. 6 TGA/DTG curves of nickel oleate (a) and cobalt oleate (b)

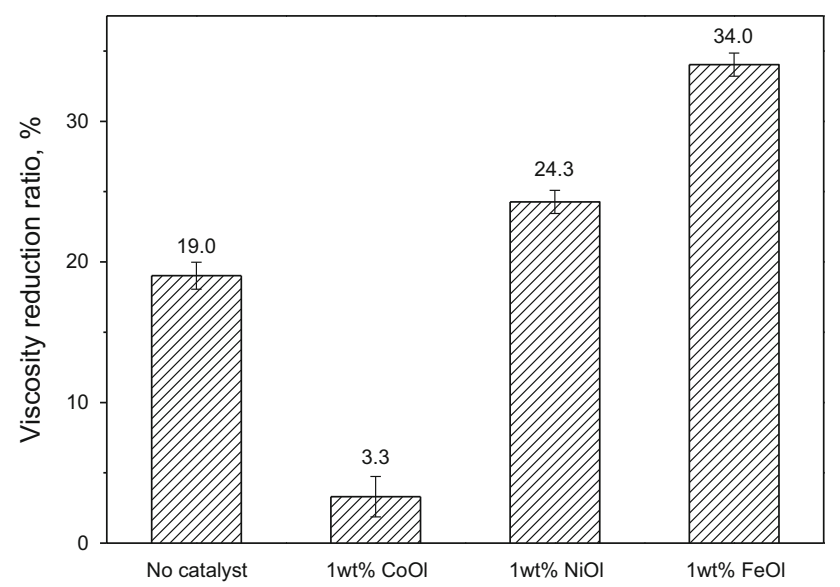

Fig. 7 Viscosity reduction ratios of $\mathrm{Fe}, \mathrm{Ni}$ and $\mathrm{Co}$ oleates

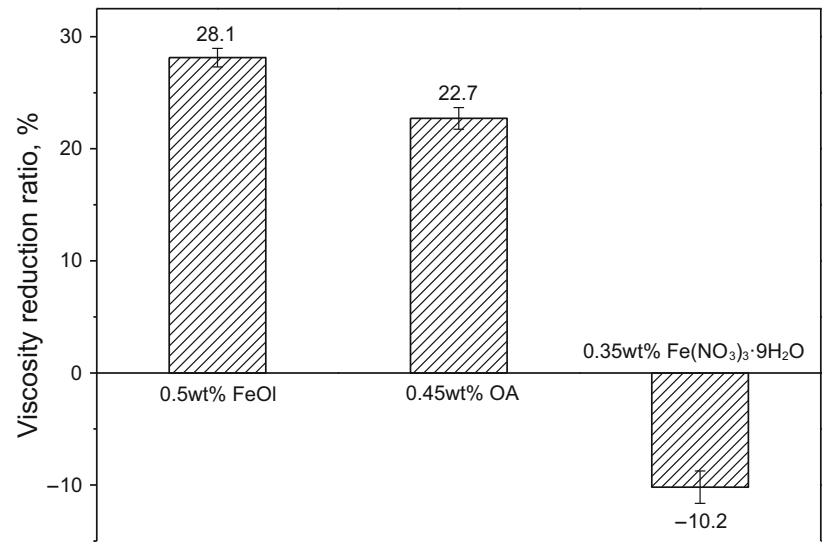

Fig. 8 Viscosity reduction ratios with ferric oleate, oleic acid and iron (III) nitrate nonahydrate

increase in the viscosity of the heavy crude oil. This could be because, under the catalytic role of iron nitrate, the high content of nitrogen could promote the polymerization of the heavy components and give rise to coke, thereby

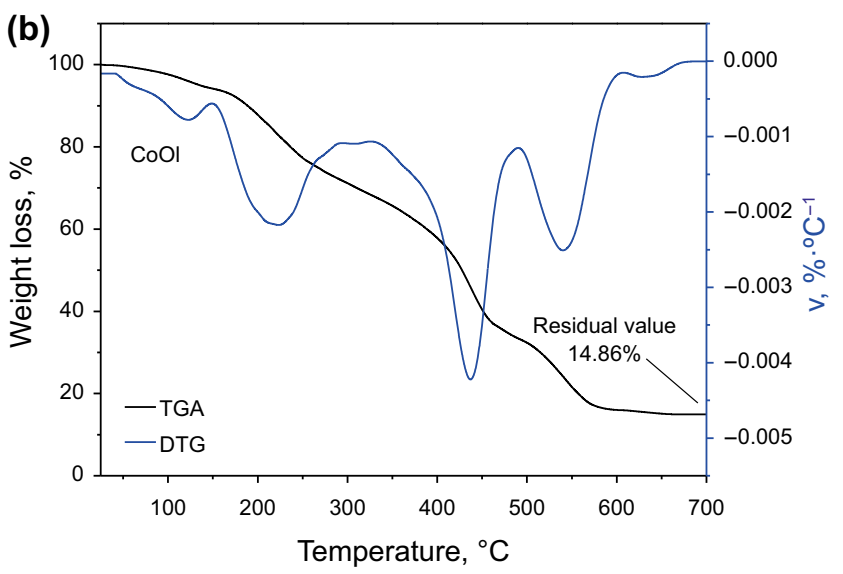

inhibiting the thermal cracking reaction and increasing the viscosity (Liang 2003).

In addition, the different catalysts containing short chain acids (lauric acid, myristic acid, oleic acid) are illustrated in Fig. 9 of the supporting information. Through comparison of the viscosity reduction ratio of the three different organic acids, we found that the oleic acid exhibited the best activity.

\subsubsection{Effect of ferric oleate dosage on the viscosity of heavy crude oil}

As shown in Fig. 10, the dosage of ferric oleate has a great effect on the viscosity change of the heavy crude oil. The viscosity reduction ratio increases gradually with the increase in ferric oleate dosage. The highest viscosity reduction ratio (up to $86.1 \%$ ) is achieved at a ferric oleate dosage of $10.0 \mathrm{wt} \%$.

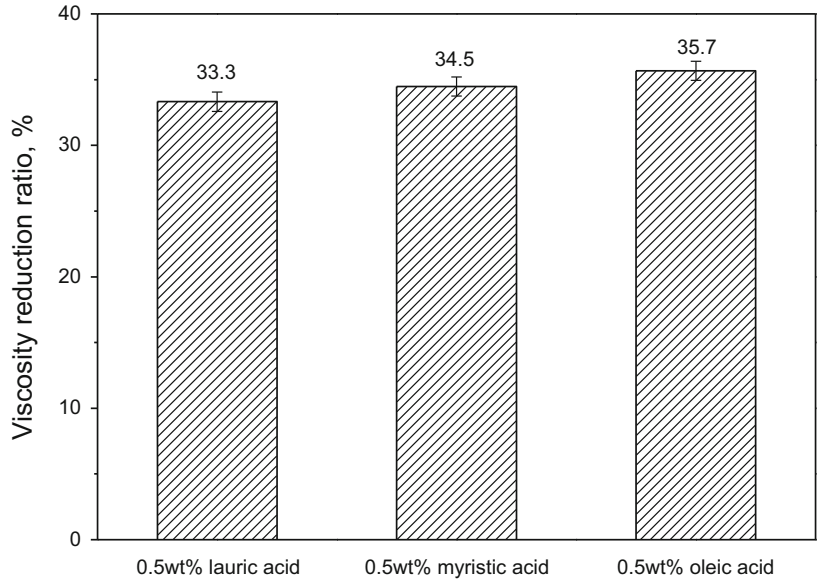

Fig. 9 The viscosity reduction ratio of oleic acid, myristic acid and lauric acid (the heavy oil used for this research from the $4 \#$ oil at Shengli Oilfield, and the viscosity of the crude oil was measured to be $171,900 \mathrm{mPa} \mathrm{s}$ at $50{ }^{\circ} \mathrm{C}$ ) 


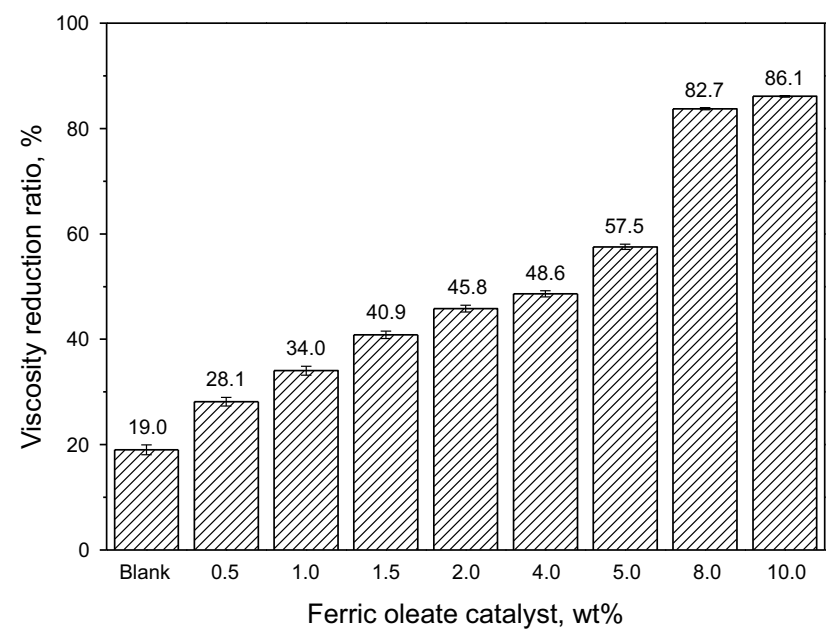

Fig. 10 Viscosity reduction ratios with different mass ratios of ferric oleate catalyst

\subsection{The change of properties before and after aquathermolysis}

\subsubsection{Analysis of SARA components}

In consideration of the efficiency and economy, the reaction system with $8.0 \mathrm{wt} \% \mathrm{FeOl}$ was selected to analyze the components of the heavy crude oil before and after aquathermolysis. The SARA components of the heavy crude oil samples are listed in Table 3. After aquathermolysis in the presence of ferric oleate, the content of the SARA components changes greatly. Namely, the content of light components increases and heavy components decrease after the aquathermolysis. This indicates that ferric oleate can promote the transformation of heavy components into light components. Besides, the content of resin decreases and the content of asphaltene increases after the aquathermolysis reaction in the presence of ferric oleate. Resin could help to promote the dispersion of asphaltene particles in heavy crude oil (Bhardwaj and Hartland 1994), and further, the ratio between resin and asphaltene could affect the stability of asphaltene ( $\mathrm{Li}$ et al. 1999; Mansoori 1997). As listed in Table 4, the ratio of resin and asphaltene decreases after aquathermolysis in the presence of ferric oleate catalyst. This means that, during the aquathermolysis reaction, ferric oleate catalyst can
Table 4 Ratios between saturates and aromatic as well as resin and asphaltene before and after aquathermolysis reaction

\begin{tabular}{lll}
\hline Sample & 3\# Oil sample & Oil after reaction \\
\hline Saturated (\%)/Aromatic (\%) & 0.95 & 0.95 \\
Resin (\%)/Asphaltene (\%) & 9.39 & 6.79 \\
\hline
\end{tabular}

promote the association and coalescence of macromolecules in asphaltene.

\subsubsection{Element analysis of heavy crude oil as well as its heavy components}

The C, H, N, S elemental content of the heavy oil and its heavy components (resin and asphaltene) before and after aquathermolysis are listed in Table 5. After the aquathermolysis reaction, the ratio of $\mathrm{N}_{\mathrm{H}} / \mathrm{N}_{\mathrm{C}}(\mathrm{H} / \mathrm{C}$ ratio, the atomic ratio of hydrogen to carbon) of the heavy crude oil increases from 1.79 to 1.94; the heteroatoms amount of $\mathrm{N}$ decreases from 0.82 to 0.77 , and the content of $\mathrm{S}$ decreases from 2.59 to 2.36. This indicates that the breaking of C-S and $\mathrm{C}-\mathrm{N}$ bonds may have happened during the hydrocracking reaction. As to the heavy components, the $\mathrm{N}$ content in the resin and asphaltene remains unchanged after the aquathermolysis reaction, and that of $\mathrm{S}$ decreases a little. This indicates that ferric oleate has a small effect on the desulfurization of the heavy components.

\subsubsection{FT-IR analysis of heavy components before and after aquathermolysis}

Figure 11 shows the FT-IR spectra of resin and asphaltene of the heavy crude oil before and after aquathermolysis. The assignments of the infrared absorbance peaks are summarized in Table 6. As to resin, the absorbance peak at $732 \mathrm{~cm}^{-1}$ is weakened and moved to a lower wavenumber region $\left(728 \mathrm{~cm}^{-1}\right)$ after the aquathermolysis reaction (Fig. 11a), possibly due to the destruction of the long side chain generating shorter chains. The peaks in the wavenumber range of $800-840 \mathrm{~cm}^{-1}(871,822$ and $748 \mathrm{~cm}^{-1}$ ) demonstrate that substitution products could be generated after the aquathermolysis reaction. Besides, as shown in Fig. 11b, ferric oleate catalyst has nearly no

Table 3 SARA components of 3\# heavy crude oil sample before and after aquathermolysis with FeOl

\begin{tabular}{lllllll}
\hline Oil sample & Saturate, wt $\%$ & Aromatic, wt $\%$ & Light component, wt $\%$ & Resin, wt\% & Asphaltene, wt\% & Heavy component, wt $\%$ \\
\hline 3\# Oil sample & 31.1 & 32.8 & 63.8 & 32.7 & 3.5 & 36.2 \\
Oil after reaction & 32.1 & 33.8 & 66.0 & 29.7 & 4.4 & 34.0 \\
\hline
\end{tabular}


Table 5 Element compositions of heavy crude oil and its heavy components before and after aquathermolysis

\begin{tabular}{llllll}
\hline Sample & $\mathrm{N}, \mathrm{wt} \%$ & $\mathrm{C}, \mathrm{wt} \%$ & $\mathrm{H}, \mathrm{wt} \%$ & $\mathrm{~S}, \mathrm{wt} \%$ & $\mathrm{~N}_{\mathrm{H}} / \mathrm{N}_{\mathrm{C}}$ \\
\hline 3\# Oil sample & 0.82 & 84.04 & 12.54 & 2.59 & 1.79 \\
Oil sample after reaction with ferric oleate & 0.77 & 83.42 & 13.45 & 2.36 & 1.94 \\
Resin before reaction & 1.38 & 84.71 & 10.74 & 3.17 & 1.52 \\
Resin after reaction with ferric oleate & 1.38 & 84.72 & 10.85 & 3.06 & 1.54 \\
Asphaltene before reaction & 1.66 & 84.40 & 10.03 & 3.91 & 1.42 \\
Asphaltene after reaction with ferric oleate & 1.66 & 85.09 & 9.70 & 3.52 & 1.37 \\
\hline
\end{tabular}

(a)

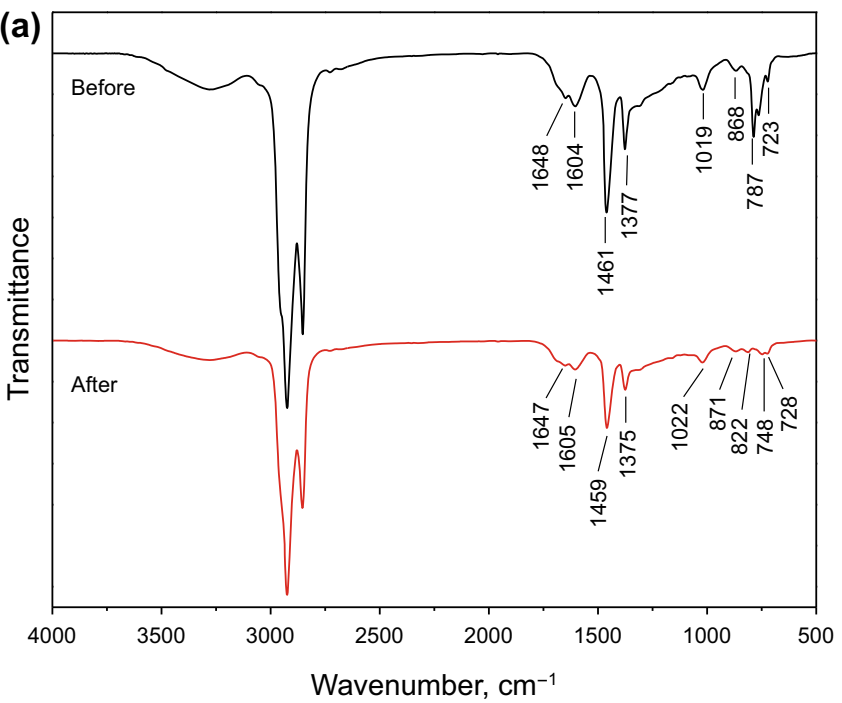

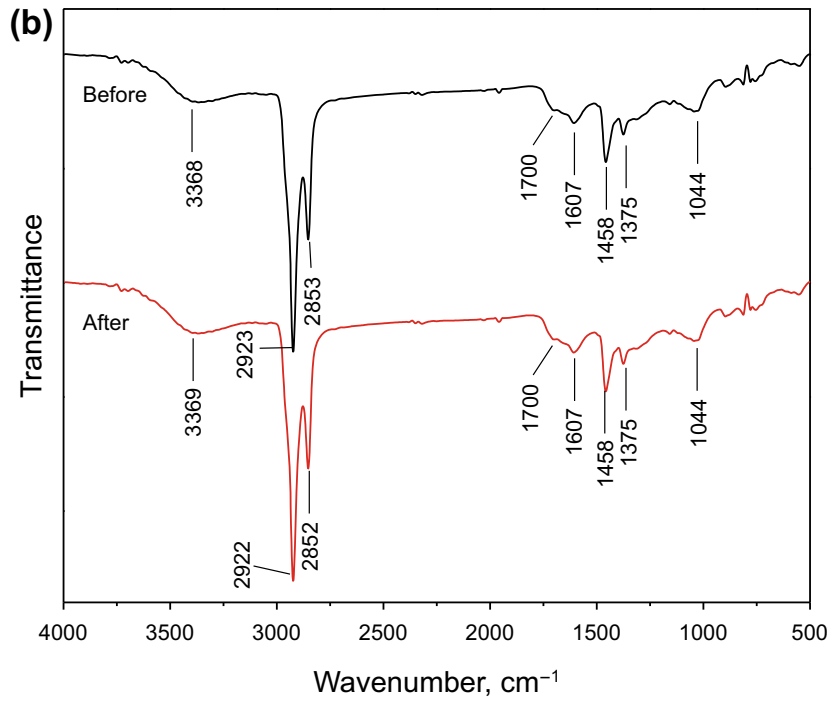

Fig. 11 FT-IR spectra of the resin (a) and asphaltene (b) before and after the reaction

Table 6 FT-IR absorbance peaks of resin and asphaltene components

\begin{tabular}{ll}
\hline Wavenumbers, $\mathrm{cm}^{-1}$ & Infrared absorption characteristic peaks and the vibrations forms \\
\hline $3500-3300$ & $-\mathrm{NH}_{2}$ or free $-\mathrm{NH}$, stretching vibration \\
$2933-2923,2860-2840$ & $-\mathrm{CH}_{2}$, symmetric and antisymmetric vibrations \\
$1680-1620$ & $\mathrm{C}=\mathrm{C}$, stretching vibration \\
$1850-1600$ & $-\mathrm{C}=\mathrm{O}$ (alcohols, aldehydes, acid and ketones, etc.), stretching vibration \\
$1470-1450$ & $-\mathrm{CH}_{3},-\mathrm{CH}_{2}$, deformation vibration \\
1608,1460 & $\mathrm{Asymmetric}$ stretching vibration of framework phenyl rings $\mathrm{C}=\mathrm{C}$ \\
$1380-1370$ & $-\mathrm{CH}_{3}$, symmetrical deformation vibration \\
$1300-1000$ & $\mathrm{C}-\mathrm{O}$, stretching vibration \\
$733-723$ & $-\left(\mathrm{CH}_{2}\right)_{n}-, n \geq 4$ \\
$800-600$ & $\mathrm{C}-\mathrm{Cl}$ \\
\hline
\end{tabular}

effect on the content of asphaltene after the aquathermolysis reaction. This is consistent with corresponding SARA data and element analysis data. According to Eq. (1), the side chain length of resin and asphaltene can be estimated from the $n_{\mathrm{CH} 2} / n_{\mathrm{CH} 3}$ ratio determined by FT-IR. In Eq. (1), $n_{\mathrm{CH} 2}$ and $n_{\mathrm{CH} 3}$ represent the number of methylene and methyl, and $S_{1460}$ and $S_{1380}$ are the feature peak area of IR spectra at 1460 and $1380 \mathrm{~cm}^{-1}$ (Liang et al. 1987). As listed in Table 7 , the $n_{\mathrm{CH} 2} / n_{\mathrm{CH} 3}$ ratio of resin tends to decrease after the aquathermolysis reaction, which proves 
Table 7 The $n_{\mathrm{CH} 2} / n_{\mathrm{CH} 3}$ ratio of resin and asphaltene before and after aquathermolysis

\begin{tabular}{lll}
\hline Sample & $\mathrm{S}_{1460} /$ & $n_{\mathrm{CH} 2} /$ \\
& $\mathrm{S}_{1380}$ & $n_{\mathrm{CH} 3}$ \\
\hline Resin before reaction & 4.190 & 2.940 \\
Resin after reaction with ferric oleate & 4.058 & 2.412 \\
Asphaltene before reaction & 4.712 & 5.028 \\
Asphaltene after reaction with ferric oleate & 4.711 & 5.024 \\
\hline
\end{tabular}

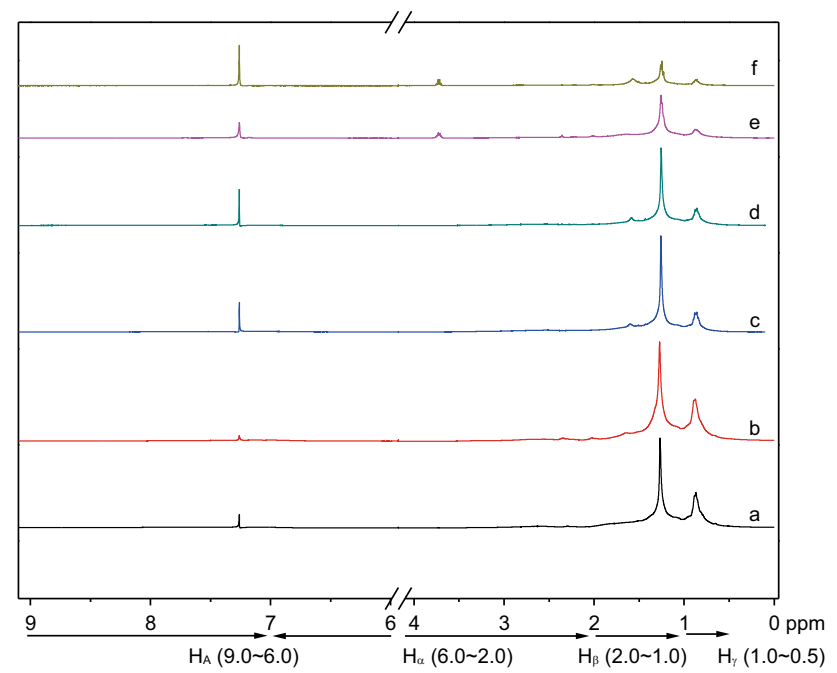

Fig. $12{ }^{1} \mathrm{H}$ NMR spectra of oil samples, resins and asphaltenes before and after reaction. a ${ }^{1} \mathrm{H}$ NMR spectra of oil sample before reaction, b ${ }^{1} \mathrm{H}$ NMR spectra of oil sample after reaction, $\mathbf{c}^{1} \mathrm{H}$ NMR spectra of resin before reaction, $\mathbf{d}{ }^{1} \mathrm{H}$ NMR spectra of resin after reaction, $\mathbf{e}^{1} \mathrm{H}$ NMR spectra of asphaltene before reaction, $\mathbf{f}^{1} \mathrm{H}$ NMR spectra of asphaltene after reaction)

assignments in the ${ }^{1} \mathrm{H}$ NMR chemical shifts were shown in Table 8. The ${ }^{1} \mathrm{H}-\mathrm{NMR}$ data $\left(\mathrm{H}_{\mathrm{A}}, \mathrm{H}_{\alpha}, \mathrm{H}_{\beta}, \mathrm{H}_{\gamma}\right)$ of the heavy crude oil samples as well as their resin and asphaltene components before and after aquathermolysis reaction are shown in Table 9. The parameters such as the aromaticity factor $\left(f_{\mathrm{A}}\right)$, aromaticity condensation $\left(\mathrm{H}_{\mathrm{AU}} / \mathrm{C}_{\mathrm{A}}\right)$, replacement rate of periphery hydrogen in the aromatic ring system $(\sigma)$ and branchiness index $(\mathrm{BI})$ were calculated by Eqs. (2)-(5), respectively (Liang et al. 1991):
$f_{\mathrm{A}}=\frac{\mathrm{C}_{\mathrm{T}} / \mathrm{H}_{\mathrm{T}}-\left(\mathrm{H}_{\alpha}+\mathrm{H}_{\beta}+\mathrm{H}_{\gamma}\right) / 2 \mathrm{H}_{\mathrm{T}}}{\mathrm{C}_{\mathrm{T}} / \mathrm{H}_{\mathrm{T}}}$

$\frac{\mathrm{H}_{\mathrm{AU}}}{\mathrm{C}_{\mathrm{A}}}=\frac{\mathrm{H}_{\mathrm{A}} / \mathrm{H}_{\mathrm{T}}+\mathrm{H}_{\alpha} / 2 \mathrm{H}_{\mathrm{T}}}{\mathrm{C}_{\mathrm{T}} / \mathrm{H}_{\mathrm{T}}-\left(\mathrm{H}_{\alpha}+\mathrm{H}_{\beta}+\mathrm{H}_{\gamma}\right) / 2 \mathrm{H}_{\mathrm{T}}}$

$\sigma=\frac{\mathrm{H}_{\alpha} / 2}{\mathrm{H}_{\mathrm{A}}+\mathrm{H}_{\alpha} / 2}$

$\mathrm{BI}=\frac{\frac{1}{3} S_{\mathrm{CH}_{3}}}{\frac{1}{2} S_{\left(\mathrm{CH}_{2}+\mathrm{CH}\right)}}$

In Eqs. (2)-(5), $\mathrm{C}_{\mathrm{T}}$ and $\mathrm{H}_{\mathrm{T}}$ represent the total amounts of carbon and hydrogen, $\mathrm{H}_{\mathrm{T}}=\mathrm{H}_{\mathrm{A}}+\mathrm{H}_{\alpha}+\mathrm{H}_{\beta}+\mathrm{H}_{\gamma}$, and $\mathrm{C}_{\mathrm{T}}$ / $\mathrm{H}_{T}$ is the ratio of carbon to hydrogen. The value of $\mathrm{C}_{T} / \mathrm{H}_{T}$ for saturated content is assumed to be 2. As seen in Eq. (3), the higher the $\mathrm{H}_{\mathrm{AU}} / \mathrm{C}_{\mathrm{A}}$ value, the lower the aromaticity condensation. In the meantime, when $\sigma$ value increases, the aromatic ring undergoes hydrogenation [Eq. (4)]. Moreover, the higher the BI value, the larger the degree of branching of macromolecular chains and the shorter the branch chain [Eq. (5)]. The detailed calculated results are summarized in Table 10.

As listed in Table 10, the aromaticity factor $\left(f_{\mathrm{A}}\right)$ of the heavy crude oil decreases after aquathermolysis, and the aromaticity condensation value $\left(\mathrm{H}_{\mathrm{AU}} / \mathrm{C}_{\mathrm{A}}\right)$ also increases. Besides, the value $(\sigma)$ of the replacement rate of periphery hydrogen in the aromatic ring system and the branchiness index (BI) increase after the aquathermolysis reaction. The decrease in the aromaticity factor indicates that the hydrogenation reaction could give rise to unsaturated components. On the contrary, the increase in the aromaticity condensation refers to a decrease in the condensation degree of the aromatic ring system as well as the occurrence of ring-opening after the aquathermolysis reaction. Moreover, the increase in the replacement rate of peripheral hydrogen in the aromatic ring system indicates that a hydrogenation reaction might occur in the aromatic ring. The increase in the branching index of the side chains indicates that the branching degree of the carbon chain increases and the side chain length decreases in association with side chain breakage after the aquathermolysis reaction.

Table 8 Assignments in the ${ }^{1} \mathrm{H}$ NMR chemical shifts

\begin{tabular}{lll}
\hline Parameter & Assignment & Chemical shift, ppm \\
\hline $\mathrm{H}_{\mathrm{A}}$ & Aromatic hydrogen & $6.0-9.0$ \\
$\mathrm{H}_{\alpha}$ & Aliphatic hydrogen attached to $\mathrm{C}_{\alpha}$ to aromatic rings & $2.0-4.0$ \\
$\mathrm{H}_{\beta}$ & Aliphatic hydrogen attached to $\mathrm{C}_{\beta}$ and the $\mathrm{CH}_{2}, \mathrm{CH}$ beyond the $\mathrm{C}_{\beta}$ to aromatic rings & $1.0-2.0$ \\
$\mathrm{H}_{\gamma}$ & Aliphatic hydrogen attached to $\mathrm{C}_{\gamma}$ and the $\mathrm{CH}_{3}$ beyond the $\mathrm{C}_{\gamma}$ to aromatic rings & $0.5-1.0$ \\
\hline
\end{tabular}


Table $9{ }^{1} \mathrm{H}$ NMR chemical shifts of oil samples, resin and asphaltene before and after reaction

\begin{tabular}{llccc}
\hline Sample & $\mathrm{H}_{\mathrm{A}}, \%$ & $\mathrm{H}_{\alpha}, \%$ & $\mathrm{H}_{\beta}, \%$ & $\mathrm{H}_{\gamma}, \%$ \\
\hline 3\# Oil sample & 3.40 & 6.57 & 59.55 & 30.58 \\
Oil sample after reaction with ferric oleate & 4.10 & 8.18 & 56.83 & 30.90 \\
Resin before reaction & 2.30 & 13.65 & 62.94 & 21.11 \\
Resin after reaction with ferric oleate & 3.71 & 12.92 & 59.32 & 24.05 \\
Asphaltene before reaction & 2.30 & 15.01 & 62.91 & 19.78 \\
Asphaltene after reaction with ferric oleate & 2.57 & 18.28 & 59.67 & 19.48 \\
\hline
\end{tabular}

Table 10 Structural parameters of heavy crude oil samples as well as their resin and asphaltene components before and after reaction

\begin{tabular}{lllll}
\hline Sample & $f_{\mathrm{A}}$ & $\mathrm{H}_{\mathrm{AU}} / \mathrm{C}_{\mathrm{A}}$ & $\sigma$ & $\mathrm{BI}$ \\
\hline 3\# Oil sample & 0.135 & 0.884 & 0.491 & 0.307 \\
Oil sample after reaction with ferric oleate & 0.070 & 2.280 & 0.499 & 0.317 \\
Resin before reaction & 0.257 & 0.539 & 0.748 & 0.184 \\
Resin after reaction with ferric oleate & 0.259 & 0.606 & 0.635 & 0.222 \\
Asphaltene before reaction & 0.301 & 0.465 & 0.765 & 0.169 \\
Asphaltene after reaction with ferric oleate & 0.333 & 0.482 & 0.781 & 0.167 \\
\hline
\end{tabular}

As to the resin component after the aquathermolysis reaction in the presence of the ferric oleate catalyst, the aromaticity condensation value increases, the value of the replacement rate of peripheral hydrogen in the aromatic ring system decreases, and the branchiness index rises. For the asphaltene component, the aromaticity condensation value and the replacement rate of the peripheral hydrogen in the aromatic ring system increase after the aquathermolysis reaction.

The above mentioned ${ }^{1} \mathrm{H}$-NMR data indicate that the introduction of ferric oleate catalyst during the aquathermolysis reaction of the heavy crude oil contributes to promoting hydrogenation, ring-opening and side chain breakage, thereby adding to the fracturing of the heavy crude oil. Particularly, the ferric oleate catalyst contributes to the ring-opening and side chain fracturing of the resin component as well as to the aromatic ring hydrogenation reaction and polymerization of the asphaltene component. And these are consistent with corresponding FT-IR, SARA and EL analysis.

\subsubsection{Water contact angle}

The heavy crude oil is a water-in-oil emulsion. The contact angle was able to illustrate the emulsification (Langevin et al. 2004). Figure 13 showed the effect of ferric oleate dosage on the water contact angle of the heavy crude oil. The water contact angle of the as-received heavy crude oil without ferric oleate is $109.1^{\circ}$, and the addition of ferric oleate catalyst up to a dosage of $4.0 \mathrm{wt} \%$ leads to increases in the water contact angles. When the dosage of ferric oleate is small, the oleic acid ligands are mainly adsorbed on the surface of oil droplets to promote the catalytic reaction. After the reaction, it will adsorb on the surface of

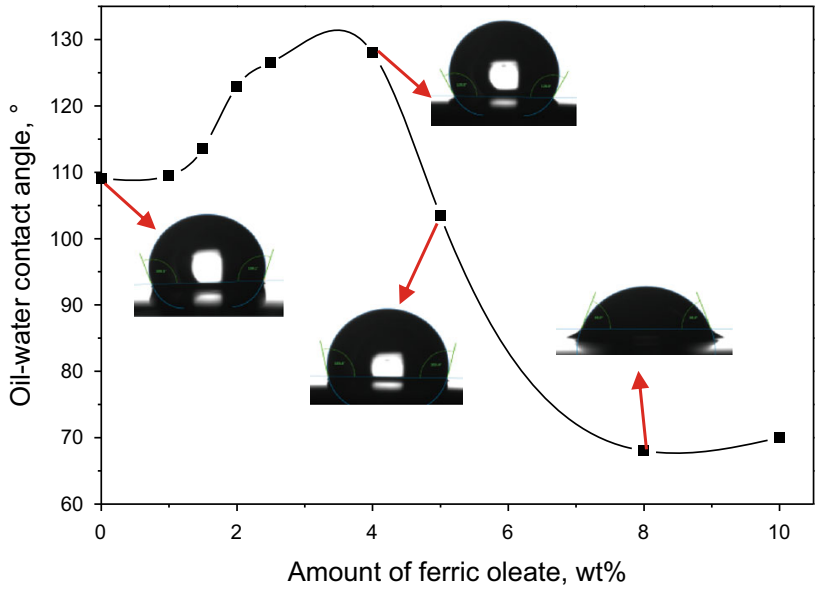

Fig. 13 Water contact angles of heavy crude oil with different contents of ferric oleate

the oil droplets to increase the contact angles. The dosage of the catalyst in the dosage range of $5.0-10.0 \mathrm{wt} \%$, however, causes decreases in the water contact angles of the tested heavy crude oil. Particularly, the lowest water contact angle is achieved at a ferric oleate dosage of $8.0 \mathrm{wt} \%$, which corresponds to the formation of an oil-inwater $(\mathrm{O} / \mathrm{W})$ emulsion. These indicate that the catalytic reaction is predominant at a low ferric oleate dosage (below $4.0 \mathrm{wt} \%$ ), while emulsification is predominant at a high ferric oleate dosage (above $5.0 \mathrm{wt} \%$ ).

\subsection{The viscosity reduction mechanism of the heavy crude oil}

In terms of the mechanism for promoting the aquathermolysis reaction of the heavy crude oil, ferric oleate 


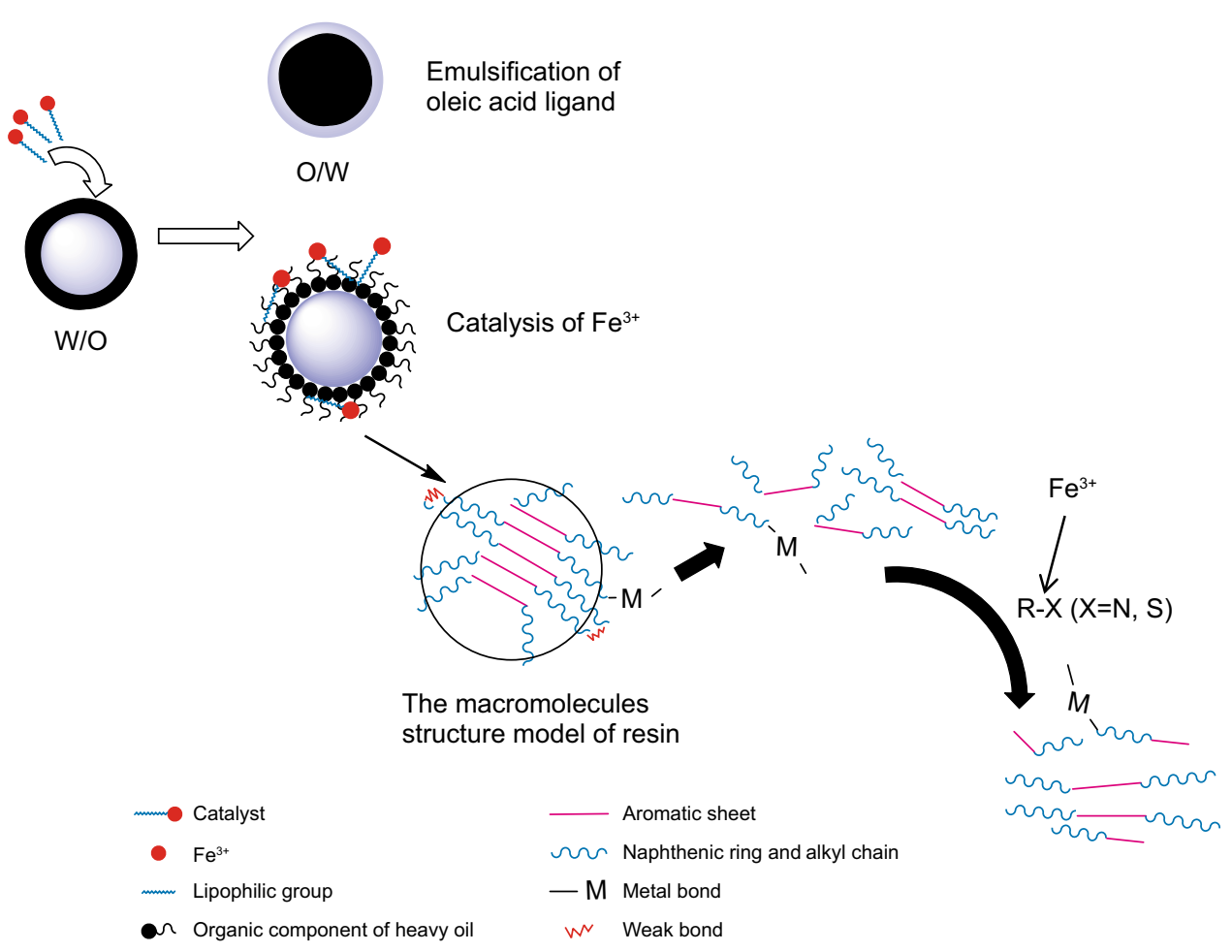

Fig. 14 Schematic diagram of action mechanism of ferric oleate catalyst

catalyst functions by the catalysis of the transition metal $\mathrm{Fe}^{3+}$ and the emulsification of oleic long-alkyl chains. Its action mechanism is schematically shown in Fig. 14. On one hand, the oleic acid ligand contributes to promoting the formation of an $\mathrm{O} / \mathrm{W}$ emulsion and increasing the contact area of the transition metal with oil, thereby effectively enhancing the aquathermolysis reaction. On the other hand, the oleic acid ligand caused the aggregation state of the resin macromolecules to be destroyed. And $\mathrm{Fe}^{3+}$ contributes to promoting the hydrogenation, polymerization, ring-opening, long side chain breakage, desulfurization and denitrification of the heavy crude oil during catalytic aquathermolysis. As a result, the heavy components are more effectively transformed into light components, leading to a reduction in the viscosity and an improvement in the quality of the heavy crude oil.

\section{Conclusions}

In summary, three oil-soluble oleates were synthesized, and their effect on the aquathermolysis reaction of the heavy crude oil extracted at Shengli Oilfield was investigated in relation to structure characterizations as well as water contact angle measurement. Results indicate that ferric oleate is more effective in reducing viscosity than nickel and cobalt oleates. The viscosity reduction ratio increases gradually with increasing dosage of ferric oleate. Particularly, the highest viscosity reduction ratio (up to $86.1 \%$ ) is achieved when the heavy crude oil is allowed to undergo aquathermolysis at $200{ }^{\circ} \mathrm{C}$ for $24 \mathrm{~h}$ in the presence of $10.0 \mathrm{wt} \%$ ferric oleate catalyst. The good ability of ferric oleate to reduce the viscosity of the heavy crude oil is attributed to the catalytic role of $\mathrm{Fe}^{3+}$ and the emulsification function of oleic longalkyl chains. Such a dual function of the ferric oleate during catalytic aquathermolysis contributes to increase the contact area of transition metal with oil and promoting the hydrogenation, polymerization, ring-opening, long side chain breakage, desulfurization and denitrification of the heavy crude oil, thereby reducing the viscosity and improving the quality of the heavy crude oil.

Acknowledgements The authors gratefully acknowledge the support of the National Natural Science Foundation of China (Nos. 21471047 and 21371047) and Natural Science Foundation of Henan Province of China (162300410014).

Open Access This article is distributed under the terms of the Creative Commons Attribution 4.0 International License (http://creative commons.org/licenses/by/4.0/), which permits unrestricted use, distribution, and reproduction in any medium, provided you give appropriate credit to the original author(s) and the source, provide a link to the Creative Commons license, and indicate if changes were made.

\section{References}

Bhardwaj A, Hartland S. Kinetics of coalescence of water droplets in water-in-crude oil emulsions. J Disper Sci Tech. 
1994;15(2):133-46. https://doi.org/10.1080/019326994089435 49.

Bronstein LM, Huang XL, Retrum J, et al. Influence of iron oleate complex structure on iron oxide nanoparticle formation. Chem Mater. 2007;19:3624-32. https://doi.org/10.1021/cm062948j.

Chen EY, Liu YJ, Liang M, et al. A study on the viscosity reduction of Liaohe heavy oil by oil soluble nickel oleate. J Daqing Pet Inst. 2010;34(6):68-71. https://doi.org/10.3969/j.issn.2095-4107. 2010.06.012.

Chivers T, Hyne JB, Lau C. The thermal decomposition of hydrogen sulfide over transition metal sulfides. Int $\mathbf{J}$ Hydrog Energy. 1980;5(5):499-506. https://doi.org/10.1016/0360-3199(80)9005 6-7.

Clark PD, Dowling NI, Lesage KL, et al. Chemistry of organosulphur compound types occurring in heavy oil sands: 5. Reaction of thiophene and tetrahydrothiophene with aqueous Group VIIIB metal species at high temperature. Fuel. 1987;66(12):1699-702. https://doi.org/10.1016/0016-2361(87)90366-8.

Clark PD, Hyne JB, Tyrer JD. Chemistry of organosulfur compound types occurring in heavy oil sands: 1. High temperature hydrolysis and thermolysis of tetrahydrothiophene in relation to steam stimulation processes. Fuel. 1983;62(8):959-62. https:// doi.org/10.1016/0016-2361(83)90170-9.

Fan ZX, Zhao FL, Wang JX, et al. Upgrading and viscosity reduction of super heavy oil by aquathermolysis with hydrogen donor. J Fuel Chem Tech. 2006. https://doi.org/10.3969/j.issn.02532409.2006.03.011.

Galukhin AV, Erokhin AA, Osin YN, et al. Catalytic aquathermolysis of heavy oil with Iron Tris(acetylacetonate): changes of heavy oil composition and in situ formation of magnetic nanoparticles. Energy Fuels. 2015;29(8):4768-73. https://doi.org/10.1021/acs. energyfuels.5b00587.

Hong FF, Yong JL, Li GZ. Studies on the synergetic effects of mineral and steam on the composition changes of heavy oil. Energy Fuels. 2001;15(6):1475-9. https://doi.org/10.1021/ef010 0911.

Huc AY. Heavy Crude Oils; From geology to upgrading, an overview. Paris: Technip; 2010. https://www.researchgate.net/ publication/263818045.

Hyne JB, Clark PD, Clarke RA, et al. Aquathermolysis of heavy oils. In: Proceedings of the 2nd international conference on heavy crude and tar sands; 1982; Caracas, Venezuela. https://www. researchgate.net/publication/284792867.

Jeon SG, Na JG, Ko CH, et al. Preparation and application of an oilsoluble CoMo bimetallic catalyst for the hydrocracking of oil sands bitumen. Energy Fuels. 2011;25(10):4256-60. https://doi. org/10.1021/ef200703t.
Langevin D, Poteau S, Hénaut I, et al. Crude oil emulsion properties and their application to heavy oil transportation. Oil Gas Sci Technol. 2004;59:511-21. https://doi.org/10.2516/ogst:2004036.

$\mathrm{Li} \mathrm{J}$, Chen Y, Liu H, et al. Influences on the aquathermolysis of heavy oil catalyzed by two different catalytic ions: $\mathrm{Cu}^{2+}$ and $\mathrm{Fe}^{3+}$. Energy Fuels. 2013;27(5):2555-62. https://doi.org/10.1021/ ef400328s.

Li S, Liu C, Que G, et al. Colloidal structures of vacuum residua and their thermal stability in terms of saturate, aromatic, resin and asphaltene composition. J Pet Sci Eng. 1999;22:37-45. https:// doi.org/10.1016/s0920-4105(98)00055-2.

Liang WJ. Heavy oil chemistry. Shandong: China University of Petroleum; 2003.

Liang WJ, Han SQ, Liu WQ. Determination of ratio of methylene and methyl in paraffinic hydrocarbons with infrared spectroscopy. Journal of East China Petroleum Institute. 1987;11(2): 86-90. http://www.wanfangdata.com.cn/details/detail.do?_type=peri o\&id=QK000002987543.

Liang WJ, Que GH, Chen YZ. Chemical composition and structure of vacuum residues of Chinese crudes II. Average structure of vacuum residues and their fractions. Acta Pet Sin: Pet Process Sect. 1991;7(4):1-11. http://www.wanfangdata.com.cn/details/ detail.do?_type=perio\&id=QK000002922969.

Maity SK, Ancheyta J, Marroquín G, et al. Catalytic aquathermolysis used for viscosity reduction of heavy crude oils: a review. Energy Fuels. 2010;24(5):2809-16. https://doi.org/10.1021/ ef $100230 \mathrm{k}$

Mansoori GA. Modeling of asphaltene and other heavy organic depositions. J Pet Sci Eng. 1997;17:101-11. https://doi.org/10. 1016/s0920-4105(96)00059-9.

Palchoudhury S, An W, Xu Y, et al. Synthesis and growth mechanism of iron oxide nanowhiskers. Nano Lett. 2011;11(3):1141-6. https://doi.org/10.1021/nl200136j.

Peng X. Experimental study on visbreaking of heavy oil by catalytic upgrading. J Chongqing Univ Sci Technol Nat Sci Ed. 2014;16(5):20-3. https://doi.org/10.3969/j.issn.1673-1980.2014. 05.006 .

Shanmugam Y, Lin FY, Chang TH, et al. Thermal decomposition of metal nitrates in air and hydrogen environments. J Phys Chem B. 2003;107:1044-7. https://doi.org/10.1021/jp026961c.

Wang YQ, Chen YL, He J, et al. Mechanism of catalytic aquathermolysis: influences on heavy oil by two types of efficient catalytic ions: $\mathrm{Fe}^{3+}$ and $\mathrm{Mo}^{6+}$. Energy Fuels. 2010;24(3): 1502-10. https://doi.org/10.1021/ef901339k.

Wen SB, Zhao YJ, Liu YJ, et al. A study on catalytic aquathermolysis of heavy crude oil during steam stimulation. Soc Pet Eng. 2007;3:1-5. https://doi.org/10.2523/106180-ms. 